\title{
Microstructure and tribomechanical properties of multilayer TiZrN/TiSiN composite coatings with nanoscale architecture by cathodic-arc evaporation
}

\author{
O. V. Maksakova ${ }^{1, \star}$ (D) S. Zhanyssov ${ }^{2}$, S. V. Plotnikov², P. Konarski ${ }^{3}$, P. Budzynski $^{4}$, \\ A. D. Pogrebnjak ${ }^{1}$, V. M. Beresnev ${ }^{5}$, B. O. Mazilin ${ }^{5}$, N. A. Makhmudov ${ }^{6}$, A. I. Kupchishin ${ }^{7}$, and \\ Ya. O. Kravchenko ${ }^{1}$ \\ ${ }^{1}$ Department of Nanoelectronics, Sumy State University, 2, Rymskogo-Korsakova st, Sumy 40007, Ukraine \\ ${ }^{2}$ D. Serikbayev East Kazakhstan State Technical University, 69, Protozanov st., 070004 Ust-Kamenogorsk, Republic of Kazakhstan \\ ${ }^{3}$ Oukasiewicz Research Network-Tele and Radio Research Institute, 11, Ratuszowa st., 03-450 Warsaw, Poland \\ ${ }^{4}$ Lublin University of Technology, 38 D, Nadbystrzycka st., 20-618 Lublin, Poland \\ ${ }^{5}$ V.N. Karazin Kharkiv National University, 4, Svobody sq., Kharkiv 61022, Ukraine \\ ${ }^{6}$ Academy of Armed Force of the Republic of Uzbekistan, 2, Parkent st., 100075 Tashkent, Uzbekistan \\ ${ }^{7}$ Abai Kazakh National Pedagogical University, 13, Dostyk ave., 050010 Almaty, Republic of Kazakhstan
}

Received: 18 August 2020

Accepted: 20 November 2020

(C) Springer Science+Business Media, LLC, part of Springer Nature 2020

\begin{abstract}
Multilayer TiZrN/TiSiN coatings were deposited on steel substrate by the cathodicarc evaporation technique. The TiZr (75:25 at. \%) and TiSi (95:5 at. \%) alloy cathodes served as evaporation sources. Scanning electron microscopy with energy-dispersive spectroscopy, secondary ion mass-spectrometry, X-ray diffraction and X-ray photoelectron spectroscopy were employed to investigate the microstructure, elemental composition, phase state and bonding structure of the deposited coatings. Nanoindentation and ball-on-disk tribology tests were used to measure the mechanical and tribological features of the coatings, such as hardness, elastic modulus, toughness, friction coefficient and wear rate. The results show that all multilayers were fcc structures with a strong preferred orientation along (111) plane. The coherent growth of the multilayers contributed to the formation of the fine-grained structure with crystallites of 9.2-11.6 nm size and a low level of residual stresses of- (3.5-5.3) GPa. All multilayer coatings exhibited high hardness up to $38.2 \pm 1.15 \mathrm{GPa}$ and elastic modulus up to $430 \pm 12.9 \mathrm{GPa}$, indicating higher resistance against plastic deformation compared to TiZrN and TiSiN films. The result of ball-on-disk wear tests showed that the multilayer sample with the best structural features (modulation period of $20.4 \mathrm{~nm}, 0.86$ at. \% of Si, the crystallite size of $9.2 \mathrm{~nm}$ and residual stress
\end{abstract}

Handling Editor: Joshua Tong.

Address correspondence to E-mail: maksakova.tereshenko@gmail.com 